\title{
Predictors of contemporary coronary artery bypass grafting outcomes
}

\author{
Richard D. Weisel, MD, ${ }^{\mathrm{a}}$ Nancy Nussmeier, MD, ${ }^{\mathrm{b}}$ Mark F. Newman, MD, ${ }^{\mathrm{c}}$ Ronald G. Pearl, MD, PhD, ${ }^{\mathrm{d}}$ \\ Andrew S. Wechsler, MD, ${ }^{\mathrm{e}}$ Giuseppe Ambrosio, MD, ${ }^{\mathrm{f}}$ Bertram Pitt, MD ${ }^{\mathrm{g}}$ Robert M. Clare, MS, ${ }^{\mathrm{c}}$ \\ Karen S. Pieper, MS, ${ }^{\mathrm{c}}$ Linda Mongero, CCP, ${ }^{\mathrm{h}}$ Tammy L. Reece, MS, ${ }^{\mathrm{c}}$ Terrence M. Yau, MD, ${ }^{\mathrm{a}}$ \\ Stephen Fremes, MD ${ }^{\mathrm{i}}$ Philippe Menasché, MD, ${ }^{\mathrm{j}}$ Armando Lira, MD, ${ }^{k, 1}$ Robert A. Harrington, MD, ${ }^{\mathrm{d}}$ \\ T. Bruce Ferguson, MD, ${ }^{\mathrm{m}}$ and the RED-CABG Executive and Steering Committees
}

\begin{abstract}
Objectives: The study objective was to identify the predictors of outcomes in a contemporary cohort of patients from the Reduction in cardiovascular Events by acaDesine in patients undergoing CABG (RED-CABG) trial. Despite the increasing risk profile of patients who undergo coronary artery bypass grafting, morbidity and mortality have remained low, and identification of the current predictors of adverse outcomes may permit new treatments to further improve outcomes.
\end{abstract}

Methods: The RED-CABG trial was a multicenter, randomized, double-blind, placebo-controlled study that deter-
mined that acadesine did not reduce adverse events in moderately high-risk patients undergoing nonemergency
coronary artery bypass grafting. The primary efficacy end point was a composite of all-cause death, nonfatal stroke,
or the need for mechanical support for severe left ventricular dysfunction through postoperative day 28. Logistic
regression modeling with stepwise variable selection identified which prespecified baseline characteristics were asso-
ciated with the primary outcome. A second logistic model included intraoperative variables as potential covariates.

Results: The 4 independent preoperative risk factors predictive of the composite end point were (1) a history of heart failure (odds ratio, 2.9); (2) increasing age (odds ratio, 1.033 per decade); (3) a history of peripheral vascular disease (odds ratio, 1.6); and (4) receiving aspirin before coronary artery bypass grafting (odds ratio, 0.5 ), which was protective. The duration of the cardiopulmonary bypass (odds ratio, 1.8) was the only intraoperative variable that contributed to adverse outcomes.

Conclusions: Patients who had heart failure and preserved systolic function had a similar high risk of adverse outcomes as those with low ejection fractions, and new approaches may mitigate this risk. Recognition of patients with excessive atherosclerotic burden may permit perioperative interventions to improve their outcomes. The contemporary risks of coronary artery bypass grafting have changed, and their identification may permit new methods to improve outcomes. (J Thorac Cardiovasc Surg 2014;148:2720-6)

From the Division of Cardiac Surgery, ${ }^{\text {a }}$ Toronto General Hospital and University of Toronto, Toronto, Ontario, Canada; Massachusetts General Hospital, ${ }^{\mathrm{b}}$ Harvard University, Boston, Mass; Duke Clinical Research Institute, ${ }^{\mathrm{c}}$ Duke University Medical Center, Durham, NC; Stanford University School of Medicine, ${ }^{\mathrm{d}}$ Palo Alto, Calif; Drexel University College of Medicine, ${ }^{\mathrm{e}}$ Philadelphia, Pa; Division of Cardiology, ${ }^{\mathrm{f}}$ University of Perugia School of Medicine, Perugia, Italy; University of Michigan School of Medicine, ${ }^{\mathrm{g}}$ Ann Arbor, Mich; New York Presbyterian - Columbia University Medical Center, ${ }^{\text {h }}$ New York, NY; Division of Cardiac Surgery, ${ }^{i}$ Sunnybrook Health Sciences Centre and University of Toronto, Toronto, Ontario, Canada; Département de Chirurgie Cardiovasculaire, ${ }^{j}$ Assistance Publique - Hôpital Européen Georges Pompidou, Hôpitaux de Paris, Université Paris Descartes, Sorbonne Paris Cité, Paris, France; formerly with Merck Sharp \& Dohme Corp, ${ }^{\mathrm{k}}$ Whitehouse Station, NJ, now with Novartis, ${ }^{1}$ Basel, Switzerland; and East Carolina Heart Institute, ${ }^{\mathrm{m}}$ Greenville, NC.

The RED-CABG study was funded by Schering-Plough (subsequently Merck Sharp \& Dohme Corp, Whitehouse Station, NJ).

Disclosures: Dr Weisel received consulting fees or honoraria from Schering-Plough/ Merck (disbursed through the Duke Clinical Research Institute) and support from Schering-Plough/Merck for travel to study-related meetings. Dr Nussmeier received consulting fees/honoraria from Schering-Plough/Merck (disbursed through the Duke Clinical Research Institute) and support from ScheringPlough/Merck for travel to study-related meetings. Dr Newman received grant support and honoraria from Schering-Plough/Merck for activities related to the RED-CABG study (all funds paid to the Duke Clinical Research Institute). Dr Pearl received consulting fees and honoraria from Schering-Plough/Merck (disbursed through the Duke Clinical Research Institute) for participating on the RED-CABG executive committee. Dr Wechsler received consulting fees or honoraria from Schering-Plough/Merck (disbursed through the Duke Clinical Research
Institute) and support from Schering-Plough/Merck for travel to study-related meetings. Dr Ambrosio received payments from Schering-Plough/Merck for travel to study meetings. Dr Pitt received honoraria for study committee activities and support for travel to study meetings from Schering-Plough/Merck; payment for consultancies from Novartis, Bayer, Takeda, AstraZeneca, Lily, Bristol-Meyers Squibb, Relypsa, BG Medicine, Amorcyte, Aurascence, Ardelyx, and Cytopherx; grants from Novartis, Medtronic, and Forrest Laboratories; and holds stock in Relypsa, BG Medicine, and Aurascence. Dr Lira was an employee of Merck Sharp \& Dohme Corp (Whitehouse Station, NJ) and now is an employee of Novartis. Dr Harrington received grant support and honoraria from Schering-Plough/Merck for activities related to the RED-CABG study; served on a Merck advisory board and received grant funding for several other clinical trials supported by Merck (all such funds paid to the Duke Clinical Research Institute); and received direct payments from Merck for consulting activities. Dr Ferguson received honoraria for study committee activities and support for travel to study meetings from Schering-Plough/Merck and received a grant from Novadaq Technologies (paid to his institution). All other authors have nothing to disclose with regard to commercial support.

Associate Editor Nevin Katz had full editorial responsibility for this manuscript, including editorial review and final decision on acceptance. The Editor was not involved in this manuscript other than as an author.

Received for publication March 25, 2014; revisions received Aug 5, 2014; accepted for publication Aug 6, 2014; available ahead of print Sept 11, 2014.

Address for reprints: Richard D. Weisel, MD, Toronto General Hospital 4N-466, Toronto, Ontario, Canada M5G 2C4 (E-mail: rweisel@uhnresearch.ca). $0022-5223 / \$ 36.00$

Copyright $(\subset) 2014$ by The American Association for Thoracic Surgery

http://dx.doi.org/10.1016/j.jtcvs.2014.08.018 


\section{Abbreviations and Acronyms \\ $\mathrm{BM}=$ bone marrow \\ CABG = coronary artery bypass grafting \\ CVD $=$ cerebrovascular disease \\ $\mathrm{EF} \quad=$ ejection fraction \\ Hct $=$ hematocrit \\ $\mathrm{HF} \quad=$ heart failure \\ $\mathrm{Hgb} \quad=$ hemoglobin \\ MI $=$ myocardial infarction \\ PCI = percutaneous coronary intervention \\ POD $=$ postoperative day \\ PVD $=$ peripheral vascular disease \\ RED-CABG $=$ Reduction in cardiovascular Events by acaDesine in patients undergoing CABG \\ SLVD $=$ severe left ventricular dysfunction}

See related commentary on pages $2727-8$.

Supplemental material is available online.

Coronary artery bypass grafting (CABG) has evolved remarkably over the last decade. Recent studies have more clearly defined the current indications for CABG distinct from percutaneous coronary interventions (PCIs). ${ }^{1,2}$ Because of the increasing complexity and disability of patients who are referred for CABG rather than $\mathrm{PCI}^{3,4}$ the predictors of the current results of $\mathrm{CABG}$ must be periodically updated to account for the changes in patient characteristics and contemporary surgical techniques. To determine the predictors of current outcomes, we evaluated the results in a recently completed multicenter trial of 3080 patients undergoing CABG (Reduction in cardiovascular Events by acaDesine in patients undergoing CABG [RED-CABG] trial). ${ }^{5}$ The goal of this report is to identify the current predictors of CABG outcomes to target interventions to improve the results. ${ }^{6,7}$

We first determined the preoperative predictors and then evaluated intraoperative variables to assess their added value to predict postoperative adverse outcomes. Innovative approaches to preoperative preparation and new intraoperative techniques may improve outcomes in the future.

\section{METHODS}

\section{Study Design and Patient Populations}

The RED-CABG trial (clinicaltrials.gov Identifier: NCT00872001) was a multicenter, randomized, double-blind, placebo-controlled, parallel-group study designed to evaluate the ability of acadesine to reduce the incidence of ischemia/reperfusion injury in moderate- to high-risk subjects undergoing nonemergency CABG. All patients in the study underwent $\mathrm{CABG}$ with cardiopulmonary bypass, had an increased risk of postoperative adverse events, and met all of the criteria for trial entry. The primary results of the trial were recently reported..$^{5}$ The baseline characteristics are provided in Table E1. Patients requiring urgent, emergency, or salvage CABG were excluded. In addition, patients with preoperative renal dysfunction (serum creatinine level $>2 \mathrm{mg} / \mathrm{dL}$ or $180 \mu \mathrm{mol} / \mathrm{L}$ ) were specifically excluded to avoid complications associated with acadesine treatment.

\section{Primary End Point}

The primary efficacy end point was a composite of the occurrence of any of the following during surgery or through postoperative day (POD) 28 : all-cause death, nonfatal stroke, or the need for mechanical support for severe left ventricular dysfunction (SLVD). Nonfatal stroke was defined as an acute focal neurologic deficit of sudden onset that was not reversible within 24 hours and was not due to an identifiable nonvascular cause accompanied by clear evidence of a new stroke on brain imaging (computed tomography scan or magnetic resonance imaging). SLVD was defined as the new use of a mechanical circulatory assist device, such as an intra-aortic balloon pump or a ventricular assist device, during or after CABG for at least 1 hour for the treatment of low cardiac output. ${ }^{8}$ Indications for using circulatory assist devices were determined by the attending physician on the basis of his/her clinical judgment and included cardiogenic shock, difficulty weaning from cardiopulmonary bypass, refractory left ventricular failure, refractory ventricular arrhythmias, and other indications that the investigators deemed necessary for treatment of low cardiac output syndrome. All efficacy end points except all-cause death were adjudicated by an independent, blinded clinical events committee.

\section{Secondary End Points}

The key secondary efficacy end point was the first occurrence of any component of the composite end point occurring during and after CABG surgery through POD 28.

\section{Statistical and Analytic Plans}

Logistic modeling was used to assess the prognostic factors for the primary composite end point of the trial through POD 28. Candidate variables for this model were selected on the basis of clinical importance and included age, gender, ejection fraction (EF), extent of coronary artery disease, preoperative evidence of cerebrovascular disease (CVD) (prior stroke, transient ischemic attack, or other CVD; carotid stenosis; carotid endarterectomy; or PCI), history of peripheral vascular disease (PVD) (prior PVD, claudication, or peripheral arterial revascularization), previous coronary intervention (CABG or PCI), history of heart failure (HF), previous myocardial infarction (MI), hypertension, hyperlipidemia, diabetes mellitus, history of cigarette smoking, history of atrial fibrillation/flutter, anemia (hemoglobin $[\mathrm{Hgb}]<11 \mathrm{~g} / \mathrm{dL}$ or hematocrit $[\mathrm{Hct}]<33 \%$ before the start of $\mathrm{CABG}$ ), and the preoperative use of clopidogrel or aspirin. Restricted cubic splines were used to examine the conformity of continuous variables with the assumption of a linear relationship to the outcome. Principle components analysis was used in an effort to consolidate information from multiple sources (eg, for history of PVD). A simple composite indicator was found to be adequate for these categories.

Stepwise selection of covariates from the candidate list of preoperative variables was performed with model inclusion and exclusion criteria of $P=.05$. Wald chi-square $P$ values and odds ratios with $95 \%$ confidence intervals were used to summarize the risk associated with the final model covariates. Figures of the adjusted relationship of each factor in the final preoperative model were generated by calculating the predicted probability and $95 \%$ confidence interval of each outcome, assuming the median value for all other factors. 
In a second stage of the modeling process, intraoperative variables were included along with the significant preprocedure covariates previously selected as potential covariates for a parsimonious model of the primary outcome (a composite of death, SLVD, or nonfatal stroke at POD 28). Stepwise selection was used, using a selection and retention criteria of $P=.05$. The candidate covariates that were considered were age, history of PVD, history of $\mathrm{HF}$, aspirin use before $\mathrm{CABG}$, last $\mathrm{Hgb}$ and Hct measurements before $\mathrm{CABG}$ end, transfusion of whole blood or packed red blood cells during the $\mathrm{CABG}$ procedure, cardioplegia type, temperature and direction (antegrade, retrograde, or combined), number of nonarterial grafts, number of arterial grafts, duration of crossclamp (in hours), duration of CPB (in hours), and atrial fibrillation before completion of the CABG procedure from the electrocardiogram recordings. Statistical analyses were performed by the coordinating center (Duke Clinical Research Institute, Durham, NC) using SAS version 9.2 (SAS Institute Inc, Cary, NC).

\section{RESULTS}

This multicenter trial provides an overview of current techniques of CABG at multiple institutions in North America and Europe. Table E1 lists the countries where CABG cases were enrolled in this study. Neither country nor continent was predictive of adverse outcomes.

\section{Preoperative Predictors of Outcome After Coronary Artery Bypass Grafting}

From the patient's perspective, the most important outcome of CABG is event-free survival. The primary composite end point of this trial was designed to represent this perspective. The primary composite end point of this trial included all-cause death, nonfatal stroke, or need for mechanical support for SLVD through POD 28. Table E2 outlines the factors evaluated to determine the independent predictors. The statistically significant preoperative predictors of adverse primary outcome (Table 1) included a history of HF, a history of PVD, and age, whereas aspirin use before $\mathrm{CABG}$ was protective.

The influence of age on the primary outcome is depicted in Figure 1, assuming the median value of history of HF or PVD (both no) and use of aspirin before CABG (yes). Increasing age was associated with an increased risk of the composite outcome. The estimated composite event rate for patients with and without a history of HF is presented in Figure 2, assuming an age of 66 years, no history of PVD, and aspirin before CABG. HF increased the risk of the composite outcome (Figure 2). Similar results were seen in the adjusted bar graph of patients with and without PVD (Figure 3) and those not receiving aspirin before CABG (Figure 4).

A history of HF was a more powerful predictor of the composite end point than EF. Among the 404 patients with HF, 260 had an EF of $30 \%$ or greater, and among the 298 patients with an EF less than 30\%, 154 did not have a history of HF. The patients with HF with an EF of $30 \%$ or greater had a greater incidence of diabetes mellitus and hypertension than patients with no HF or patients with
TABLE 1. Composite of death, severe left ventricular dysfunction, or nonfatal stroke to postoperative day 28: Independent predictors of the primary composite outcome: All-cause death, need for mechanical support for severe left ventricular dysfunction, or nonfatal stroke to postoperative day 28

Analysis of maximum likelihood estimates

\begin{tabular}{lclrr}
\hline \multicolumn{1}{c}{ Parameter } & Odds ratio & \multicolumn{2}{c}{$\mathbf{9 5 \% \text { Wald }}$ confidence limits } & $\boldsymbol{P}$ value \\
\hline History of HF & 2.905 & 2.006 & 4.208 & $<.0001$ \\
Age (per 10-y increase) & 1.033 & 1.013 & 1.053 & .0011 \\
History of PVD & 1.621 & 1.115 & 2.357 & .0115 \\
Aspirin before CABG & 0.501 & 0.328 & 0.766 & .0014 \\
\hline
\end{tabular}

$\overline{C A B G}$, Coronary artery bypass grafting; $H F$, heart failure; $P V D$, peripheral vascular disease.

$\mathrm{HF}$ and an EF less than $30 \%$, suggesting that these patients may have had diastolic dysfunction. The patients with a low EF who did not have HF had the lowest incidence of diabetes and PVD.

PVD may have contributed to adverse outcomes because of an increased atherosclerotic burden. The majority of patients with PVD (355/483 [73\%]) had claudication or previous vascular interventions. Patients with PVD were more likely to be smokers $(79 \%)$ than patients without PVD (59\%).

The rate of the composite outcome was approximately twice as high among patients not receiving aspirin $(8.72 \%)$ compared with patients receiving aspirin $(4.58 \%)$ preoperatively. More of the patients taking aspirin preoperatively also were receiving clopidogrel $(40 \%$ vs $23 \%$ ), and fewer of the patients taking aspirin were anemic $(\mathrm{Hgb}<11$ or $\mathrm{Hct}<33)$ before surgery $(16 \%$ vs $18 \%)$. Clopidogrel was considered as a potential covariate in our model but was not found to be statistically significant

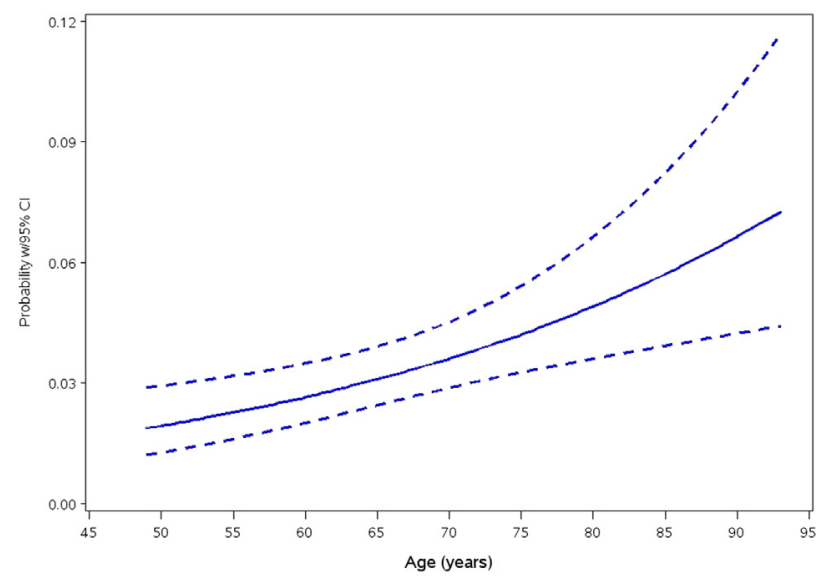

FIGURE 1. Adjusted association between age and primary composite end point. The figure plots increasing age against the estimated event rates for the primary composite outcome, assuming the median value of history of HF (no) and history of PVD (no) and use of aspirin before CABG (yes). Increasing age was associated with an increased risk of the composite outcome. $C I$, Confidence interval. 


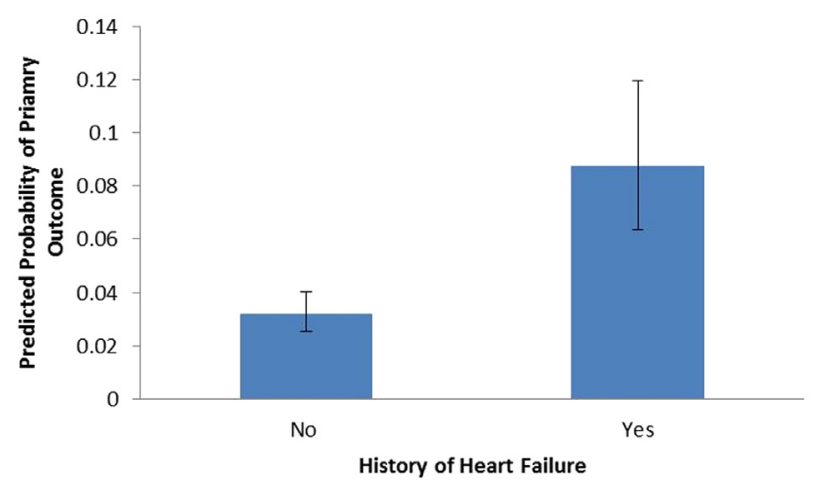

FIGURE 2. Adjusted association between HF and primary composite end point. Estimated event rates for patients with and without a history of HF, assuming an age of 66 years, no history of PVD, and aspirin before CABG. The risk of the composite outcome was greater in patients with HF.

unadjusted or after adjustment for other covariates, including aspirin use.

Tables 2-4 summarize the performance of the preoperative predictors of the composite end point when applied to the individual components of death, stroke, and SLVD, respectively. The 4 preoperative predictors of the composite outcome selected by stepwise methods also were significant in modeling early (28-day) mortality. When applied to the stroke component, only the covariates age and a history of PVD were significant. Of note, PVD was more predictive than a history of CVD.

\section{Preoperative and Intraoperative Predictors of Coronary Artery Bypass Grafting Outcome}

Although preoperative predictors can be used to counsel patients and their relatives about the risks of surgery, intraoperative predictors may influence decisions about postoperative surveillance and treatments. Therefore, we evaluated candidate predictors considering both

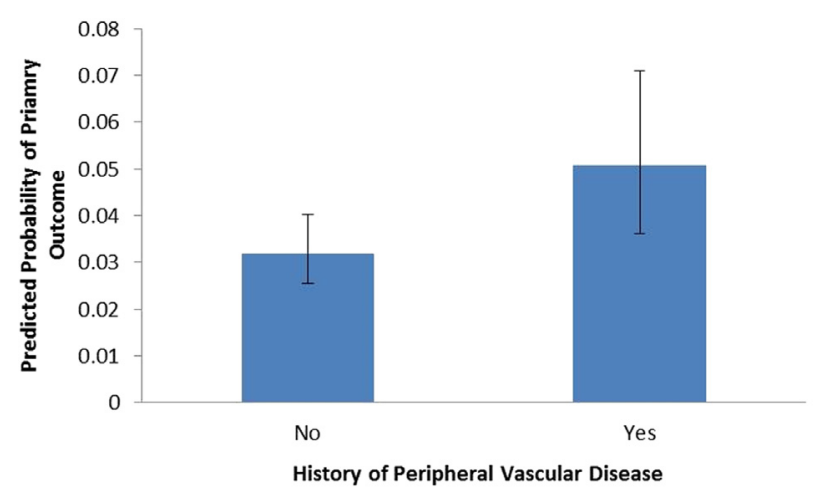

FIGURE 3. Adjusted association between PVD and primary composite end point. The estimated event rates for patients with and without a history of PVD are presented, assuming an age of 66 years, no history of $\mathrm{HF}$, and aspirin before CABG. The risk of the composite outcome was greater in patients with PVD.

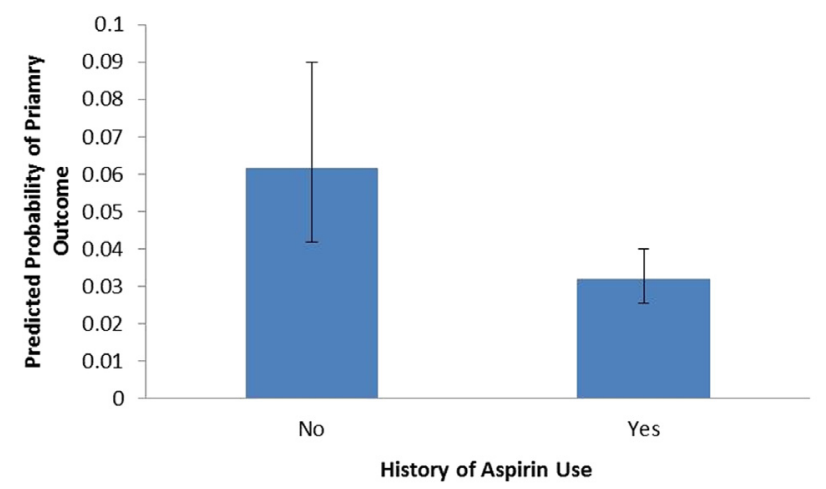

FIGURE 4. Adjusted association between preoperative aspirin and primary composite end point. The estimated event rates for patients with and without preoperative aspirin treatment, assuming an age of 66 years and no history of HF or PVD. The risk of the composite outcome was lower for those who were taking aspirin preoperatively.

preoperative variables previously identified as significant predictors and intraoperative variables, which are listed in Table E2. The results of this analysis are presented in Table 5. In addition to the 4 factors identified as preoperative predictors, the intraoperative factor identified was the duration of the cardiopulmonary bypass.

\section{Factors Not Predictive in the Multivariable Model}

Many factors that were previously predictive of CABG outcomes were no longer predictive in this recent cohort (Table E3). Previous PCI was not a univariate predictor of the composite end point $(P=.634)$, but previous CABG was a univariate predictor $(P=.036)$. Neither previous $\mathrm{PCI}$ nor previous $\mathrm{CABG}$ was an independent predictor.

Patients with a history of preoperative CVD (35\% of the population) had a trend toward a higher incidence of the composite end point $(5.91 \%)$ compared with those who did not have CVD $(4.41 \%, P=.063$ by univariate analysis $)$. However, a history of CVD was not as predictive as PVD and was not statistically significant in the multivariable model of the composite end point. Histories of hypertension, hyperlipidemia, diabetes, and smoking were frequent in this CABG population, but did not contribute

TABLE 2. Death at postoperative day 28: Independent predictors of all-cause mortality to day 28

\begin{tabular}{|c|c|c|c|c|}
\hline \multicolumn{5}{|c|}{ Analysis of maximum likelihood estimates } \\
\hline Parameter & Odds ratio & $\begin{array}{r}95^{\circ} \\
\text { confid }\end{array}$ & $\begin{array}{l}\text { ald } \\
\text { limits }\end{array}$ & $P$ value \\
\hline History of HF & 1.929 & 1.022 & 3.641 & .0428 \\
\hline Age (per 10-y increase) & 1.034 & 1.002 & 1.067 & .0353 \\
\hline History of PVD & 1.724 & 0.954 & 3.118 & .0714 \\
\hline Aspirin before $\mathrm{CABG}$ & 0.316 & 0.176 & 0.566 & .0001 \\
\hline
\end{tabular}

$C A B G$, Coronary artery bypass grafting; $H F$, heart failure; $P V D$, peripheral vascular disease. 
TABLE 3. Stroke at postoperative day 28: Independent predictors of stroke to day 28

\begin{tabular}{|c|c|c|c|c|}
\hline \multicolumn{5}{|c|}{ Analysis of maximum likelihood estimates } \\
\hline Parameter & Odds ratio & $\begin{array}{r}95 \% \\
\text { confide }\end{array}$ & $\begin{array}{l}\text { ald } \\
\text { limits }\end{array}$ & $P$ value \\
\hline History of HF & 1.288 & 0.621 & 2.672 & .4966 \\
\hline Age (per 10-y increase) & 1.036 & 1.003 & 1.070 & .0308 \\
\hline History of PVD & 1.926 & 1.058 & 3.504 & .0320 \\
\hline Aspirin before CABG & 0.855 & 0.382 & 1.915 & .7032 \\
\hline
\end{tabular}

significantly to the final model. Preoperative atrial fibrillation was more common among patients who experienced the composite outcome $(13 \%)$ compared with those who $\operatorname{did}$ not $(8 \%, P=.018)$, but that history was not an independent predictor. In some patients, atrial fibrillation may have been a late manifestation of HF with cardiac dilatation. Preoperative anemia $(\mathrm{Hgb}<11$ or $\mathrm{Hct}<33)$ was found in $16 \%$ of the patients, and the anemic patients had a higher proportion of the composite outcome, 7.4\% (33/445 patients) compared with $4.6 \%$ for the nonanemic patients $(118 / 2297, P=.016)$.

Potentially important predictors of outcome that were not in the final models included not only preoperative anemia but also intraoperative $\mathrm{Hgb}$ concentrations and transfusions (Table E3), and none were independently predictive of outcomes. A variety of myocardial protection techniques were used, but none of the alternative approaches independently influenced the outcomes.

\section{DISCUSSION}

This report documents the risk factors predictive of adverse events in a large contemporary multinational series of patients undergoing CABG from the RED-CABG trial. The 4 independent preoperative predictors of the composite end point (at 28 days: death, nonfatal stroke, and SLVD) were (1) a history of HF; (2) age; (3) a history of PVD; and (4) not receiving aspirin before CABG. Many of the risk factors that were important in previous eras of $\mathrm{CABG}$ surgery were no longer significant in this contemporary report. A remarkable finding was the low rates of mortality

TABLE 4. Severe left ventricular dysfunction at postoperative day 28: Independent predictors of need for mechanical support for severe left ventricular dysfunction to day 28

\begin{tabular}{lccrr}
\hline \multicolumn{1}{c}{ Parameter } & Odds ratio & $\begin{array}{c}\mathbf{9 5} \% \text { Wald } \\
\text { confidence limits }\end{array}$ & $\boldsymbol{P}$ value \\
\hline History of HF & 6.470 & 3.969 & 10.547 & $<.0001$ \\
Age (per 10-y increase) & 1.013 & 0.985 & 1.041 & .3731 \\
History of PVD & 1.043 & 0.577 & 1.883 & .8903 \\
Aspirin before CABG & 0.478 & 0.260 & 0.881 & .0181 \\
\hline$C A B G$, Coronary artery bypass grafting; $H F$, heart failure; $P V D$, peripheral vascular \\
disease.
\end{tabular}

TABLE 5. Independent predictors of composite outcome including preoperative and intraoperative variables

\begin{tabular}{|c|c|c|c|c|}
\hline \multicolumn{5}{|c|}{ Analysis of maximum likelihood estimates } \\
\hline Parameter & Odds ratio & $\begin{array}{r}95 \% \\
\text { confide }\end{array}$ & $\begin{array}{l}\text { ald } \\
\text { limits }\end{array}$ & $P$ value \\
\hline History of HF & 2.731 & 1.871 & 3.986 & $<.0001$ \\
\hline Duration of $\mathrm{CPB}$ & 1.774 & 1.460 & 2.156 & $<.0001$ \\
\hline Age (per 10-y increase) & 1.039 & 1.019 & 1.059 & .0001 \\
\hline Aspirin before CABG & 0.445 & 0.288 & 0.686 & .0002 \\
\hline History of PVD & 1.677 & 1.147 & 2.451 & .0076 \\
\hline
\end{tabular}

$C A B G$, Coronary artery bypass grafting; $H F$, heart failure; $P V D$, peripheral vascular disease; $C P B$, cardiopulmonary bypass.

and morbid events, which were consistent across the contributing sites. Careful attention to these preoperative risk factors may identify methods to further reduce the risks of CABG. Awareness of these risk factors may alter perioperative approaches, such as ensuring that nearly all patients receive preoperative aspirin. We also evaluated intraoperative variables and found that prolonged bypass time was predictive of more postoperative complications. Efforts to avoid complications that extend bypass duration may improve outcomes.

In this study, $\mathrm{HF}$ but not $\mathrm{EF}$ was an independent risk factor for adverse outcomes. Patients with HF but preserved systolic function are increasingly recognized as high risk for morbidity and mortality with revascularization, ${ }^{9,10}$ but the influence of this condition on the outcomes of CABG has been infrequently described. Hypertensive and diabetic patients have a greater prevalence of HF despite preservation of systolic function, and dyspnea or fatigue may result from left ventricular diastolic dysfunction. ${ }^{10}$ Therefore, cardiac surgeons should pay particular attention to patients with HF with preserved systolic function. Careful preoperative assessment may identify the underlying cardiac diastolic dysfunction and pulmonary, endocrine, or renal abnormalities that would permit interventions to mitigate this important risk factor. Attention to meticulous myocardial protection and expeditious operations may improve outcomes in this population. Reducing the intraoperative crystalloid load may reduce early postoperative cardiac edema and improve outcomes in these patients. ${ }^{11,12}$ Incomplete protection and prolonged procedures increase postoperative cardiac edema, ${ }^{11,12}$ which could exacerbate diastolic dysfunction and increase the risks of postoperative adverse events.

The increasing age of those presenting for $\mathrm{CABG}^{3,7}$ mirrors the aging population, which is anticipated to continue to increase in the next decade. The reasons for the increased risk in older patients have not been fully elucidated, but stem cell dysfunction in older patients undergoing $\mathrm{CABG}$ may contribute to their limited healing capacity. ${ }^{13,14}$ The recent National Institutes of Health Effectiveness of Stem Cell Treatment for Adults With 
Ischemic Cardiomyopathy (the FOCUS Study) by the Cardiovascular Cell Therapy Research Network (CCTRN) trial $^{15}$ documented the bone marrow (BM) stem cell dysfunction in older patients with poor ventricular function after an MI. The number of patients with active BM stem cells was found to decrease with increasing age, but some elderly patients had active BM stem cells and some younger patients did not. ${ }^{16,17}$ In the near future, we may be able to identify patients who have stem cell dysfunction and rejuvenate their BM stem cells to restore their reparative capacity. ${ }^{13,14,16,17}$

The increased risk in those who did not receive aspirin preoperatively has been reported. In a prospective placebo-controlled randomized trial of preoperative aspirin, Deja and colleagues ${ }^{18}$ followed patients for up to 6 years after CABG and found that preoperative aspirin decreased both the risk of a major cardiac events (MI or repeated revascularization, $P=.046)$ and the composite of death, MI, or revascularization $(P=.06)$. Bybee and colleagues ${ }^{19}$ retrospectively reviewed 1636 patients undergoing primary CABG and reported that preoperative aspirin reduced the hospital mortality $(P=.007)$ without increasing the risk of bleeding. Mangano ${ }^{20}$ reported that aspirin administration before or within 48 hours after revascularization surgery was associated with a $68 \%$ reduction in overall mortality and substantially reduced the rates of ischemic complications in the heart (44\% reduction in fatal and nonfatal MI or congestive $\mathrm{HF})$, the brain $(62 \%$ reduction in fatal and nonfatal stroke or encephalopathy), the kidneys $(60 \%$ reduction in renal dysfunction or failure), and the intestines ( $70 \%$ reduction in ischemia or infarction). Therefore, the benefits of preoperative and early postoperative aspirin are well supported.

Previous studies documented the detrimental influence of PVD on CABG outcomes. Both the Syntax Trial ${ }^{21}$ and the study by Algarni and colleagues ${ }^{3}$ found that PVD was an independent predictor of adverse long-term outcomes after CABG. In addition to mortality, patients with an extensive atherosclerotic burden have an increased risk of stroke, perhaps because aortic atherosclerosis is a source for cerebral emboli. ${ }^{22}$ PVD, and not a history of CVD, was an independent determinant of stroke, perhaps because patients with CVD had preoperative interventions (eg, carotid stenting or carotid endarterectomy surgery) or received careful intraoperative monitoring (including increased perfusion pressures on bypass), which may have reduced their risk of stroke with $\mathrm{CABG}^{23}$ However, patients with extensive aortic atherosclerosis have an increased risk of stroke with any surgical approach that requires aortic manipulation. ${ }^{22}$

Prolonged CPB time has been reported to correlate with adverse outcomes. ${ }^{3,7}$ Reasons for prolonged CPB times include operator facility, intraoperative problems with diffuse coronary disease that may strain the capability of myocardial protection, bleeding due to tissue disruption, or early ventricular dysfunction requiring multiple interventions before separation from the bypass circuit. Extended efforts to control bleeding or repair disrupted friable tissues may be associated with adverse outcomes. Awareness of the adverse influence of prolonged CPB duration may permit surgical teams to avoid timeconsuming complications.

The initial report of this trial indicated that the majority of patients were within the highest 3 quintiles of the Society of Thoracic Surgeons risk score. This report provides additional risk prediction to that achieved with the Society of Thoracic Surgeons calculator.

Predictors of CABG outcomes that were previously important were not significant in this study because of the limited power of the study or changes to current surgical techniques. Preoperative anemia was previously reported to increase the risk of $\mathrm{CABG}^{24}{ }^{24}$ This trial excluded patients undergoing urgent $\mathrm{CABG}$ or within 5 days of an MI, and these patients contributed to many of the anemic patients in previous reports. In this series of mostly elective but moderately high-risk patients, preoperative anemia, intraoperative anemia, and the need for blood transfusions were not independently predictive of outcomes.

A recent meta-analysis found that blood was superior to crystalloid cardioplegia and that tepid was better than warm blood cardioplegia in most randomized clinical trials. ${ }^{25}$ However, although bypass time was an independent predictor, the type of myocardial protection was not significantly associated with adverse outcomes. Either this study lacks sufficient power to distinguish among the various cardioplegic combinations or cardiac surgeons have optimized their approaches to myocardial protection and developed permutations of temperature, composition, and delivery to meet the needs of each individual patient, such that none of the individual approaches are no longer predictive of outcomes. We were surprised to find little regional variation in the primary outcomes of the trial, and region was not a univariable or multivariable predictor of any of the outcomes studied. In addition, we did not find that diabetes mellitus added to the early risk of adverse outcomes, similar to the report of the FREEDOM Trial. ${ }^{4}$ Consistent with recent reports, hypertension, hyperlipidemia, smoking, and a history of atrial fibrillation did not influence early outcomes of CABG, although these factors will have an effect on intermediate- and long-term outcomes. ${ }^{1-4}$ Left main stenosis, reoperative CABG, and previous PCI have not been important predictors for many years. ${ }^{1-4,26}$

\section{Study Limitations}

A major limitation of this report is that the trial was intended to evaluate the effects of acadesine and not to determine the predictors of adverse outcomes. However, the investigators initiated this substudy to use the extensive 
data collected in this large trial. Another limitation of the current study is the lack of inclusion of patient populations commonly seen by cardiac surgeons, including those undergoing combined valve and CABG surgery, and those with recent MI. However, the uniform patient characteristics and large multinational patient population provide current predictors and permit the identification of interventions to modify adverse outcomes.

\section{CONCLUSIONS}

This study provides a snapshot of the predictors of adverse outcomes in a large contemporary cohort of patients undergoing $\mathrm{CABG}$. The independent preoperative predictors of adverse outcome were preexisting HF, PVD, advancing age, and no preoperative aspirin. As anticipated, age and PVD predicted stroke, whereas a history of HF predicted SLVD. This information identifies new targets for quality improvement that may further reduce the risks of CABG surgery.

\section{References}

1. Farooq V, van Klaveren D, Steyerberg EW, Meliga E, Vergouwe Y, Chieffo A, et al. Anatomical and clinical characteristics to guide decision making between coronary artery bypass surgery and percutaneous coronary intervention for individual patients: development and validation of SYNTAX score II. Lancet. 2013;381:639-50.

2. Hillis LD, Smith PK, Anderson JL, Bittl JA, Bridges CR, Byrne JG, et al. 2011 ACCF/AHA guideline for coronary artery bypass graft surgery: a report of the American College of Cardiology Foundation/American Heart Association Task Force on Practice Guidelines. J Am Coll Cardiol. 2011;58:e123-210.

3. Algarni KD, Elhenawy AM, Maganti M, Collins S, Yau TM. Decreasing prevalence but increasing importance of left ventricular dysfunction and reoperative surgery in prediction of mortality in coronary artery bypass surgery: trends over 18 years. J Thorac Cardiovasc Surg. 2012;144:340-6.

4. Farkouh ME, Domanski M, Sleeper LA, Siami FS, Dangas G, Mack M, et al; for the FREEDOM Trial Investigators. Strategies for multivessel revascularization in patients with diabetes. $N$ Engl J Med. 2012;367:2375-84.

5. Newman MF, Ferguson TB, White JA, Ambrosio G, Koglin J, Nussmeier NA, et al. Effect of adenosine-regulating agent acadesine on morbidity and mortality associated with coronary artery bypass grafting: the RED-CABG randomized controlled trial. JAMA. 2012;308:157-64.

6. Ferguson TB, Peterson ED, Coombs LP, Eiken MC, Carey ML, Grover FL, DeLong ER. Society of Thoracic Surgeons and the National Cardiac Database: use of continuous quality improvement to increase use of process measures in patients undergoing coronary artery bypass graft surgery. JAMA. 2003;290: 49-56.

7. Likosky DS, Goldberg JB, DiScipio AW, Kramer RS, Groom RC, Leavitt BJ, et al; Northern New England Cardiovascular Disease Study Group. Variability in surgeons' perioperative practices may influence the incidence of low-output failure after coronary artery bypass grafting surgery. Circ Cardiovasc Qual Outcomes. 2012;5:638-44.

8. Rao V, Ivanov J, Weisel RD, Ikonomidis JS, Christakis GT, David TE. Predictors of low cardiac output syndrome after coronary artery bypass. J Thorac Cardiovasc Surg. 1996;112:38-51.
9. Bhatia RS, Tu JV, Lee DS, Austin PC, Fang J, Haouzi A, et al. Outcome of heart failure with preserved ejection fraction in a population-based study. $N$ Engl $J$ Med. 2006;355:260-9.

10. Shah AM, Pfeffer MA. The many faces of heart failure with preserved ejection fraction. Nat Rev Cardiol. 2012;9:555-6.

11. Algarni KD, Weisel RD, Caldarone CA, Maganti M, Tsang K, Yau TM. Microplegia during $\mathrm{CABG}$ was associated with less low cardiac output syndrome: a propensity matched comparison. Ann Thorac Surg. 2013;95:1532-8.

12. Amirhamzeh MM, Dean DA, Jia CX, Cabreriza SE, Starr JP, Sardo MJ, et al. Iatrogenic myocardial edema: increased diastolic compliance and time course of resolution in vivo. Ann Thorac Surg. 1996;62:737-43.

13. Brunt KR, Zhang Y, Mihic A, Li M, Li S-H, Xue P, et al. Role of wnt/ $\beta$-catenin signaling in rejuvenating myogenic differentiation of aged mesenchymal stem cells from cardiac patients. Am J Pathol. 2012;181:2067-78.

14. Zhuo Y, Li SH, Chen MS, Wu J, Kinkaid HY, Fazel S, et al. Aging impairs the angiogenic response to ischemic injury and the activity of implanted cells: combined consequences for cell therapy in older recipients. J Thorac Cardiovasc Surg. 2010;139:1286-94.

15. Perin EC, Willerson JT, Pepine CJ, Henry TD, Ellis SG, Zhao DX, et al; Cardiovascular Cell Therapy Research Network (CCTRN). Effect of transendocardial delivery of autologous bone marrow mononuclear cells on functional capacity, left ventricular function, and perfusion in chronic heart failure: the FOCUS-CCTRN trial. JAMA. 2012;307:1717-26.

16. Li S-H, Sun Z, Brunt KR, Shi X, Chen M-S, Weisel RD, Li R-K. Reconstitution of aged bone marrow with young cells repopulates cardiac-resident bone marrow derived progenitor cells and prevents cardiac dysfunction after a myocardial infarction. Eur Heart J. 2013;34:1157-67.

17. Kang K, Sun L, Xiao Y, Li S-H, Wu J, Guo J, et al. Aged human cells rejuvenated by cytokine-enhancement of biomaterials for surgical ventricular restoration. J Am Coll Cardiol. 2012;60:2237-49.

18. Deja MA, Kargul T, Domaradzki W, Stącel T, Mazur W, Wojakowski W, et al. Effects of preoperative aspirin in coronary artery bypass grafting: a doubleblind, placebo-controlled, randomized trial. J Thorac Cardiovasc Surg. 2012; 144:204-9.

19. Bybee KA, Powell BD, Valeti U, Rosales AG, Kopecky SL, Mullany C, Wright RS. Preoperative aspirin therapy is associated with improved postoperative outcomes in patients undergoing coronary artery bypass grafting. Circulation. 2005;112(Suppl I):I286-92.

20. Mangano DT. Aspirin and mortality from coronary bypass surgery. $N$ Engl J Med. 2002;347:1309-17.

21. Mohr FW, Morice MC, Kappetein AP, Feldman TE, Ståhle E, Colombo A, et al. Coronary artery bypass graft surgery versus percutaneous coronary intervention in patients with three-vessel disease and left main coronary disease: 5-year follow-up of the randomised, clinical SYNTAX trial. Lancet. 2013;381:629-38.

22. Tarakji KG, Sabik JF III, Bhudia SK, Batizy LH, Blackstone EH. Temporal onset, risk factors, and outcomes associated with stroke after coronary artery bypass grafting. JAMA. 2011;305:381-90.

23. Shishehbor MH, Venkatachalam S, Sun Z, Rajeswaran J, Kapadia SR, Bajzer C, et al. A direct comparison of early and late outcomes with three approaches to carotid revascularization and open heart surgery. J Am Coll Cardiol. 2013;62: 1948-56.

24. Engoren M, Schwann TA, Habib RH, Neill SN, Vance JL, Likosky DS. The independent effects of anemia and transfusion on mortality after coronary artery bypass. Ann Thorac Surg. 2014;97:514-20.

25. Guru V, Omura J, Alghamdi AA, Weisel RD, Fremes SE. Is blood superior to crystalloid cardioplegia? a meta-analysis of randomized clinical trials. Circulation. 2006;114(Suppl I):331-8.

26. Davierwala PM, Maganti M, Yau TM. Decreasing significance of left ventricular dysfunction and reoperative surgery in predicting coronary artery bypass grafting-associated mortality: a twelve-year study. J Thorac Cardiovasc Surg. 2003; 126:1335-44. 


\section{ROLE OF THE SPONSOR}

The executive and steering committees, composed of members from academia and the study sponsor, were responsible for the overall design, conduct, and supervision of the study. Schering-Plough (subsequently Merck Sharp $\&$ Dohme Corp) funded the research.

\section{RED-CABG EXECUTIVE COMMITTEE}

Giuseppe Ambrosio, MD, University of Perugia School of Medicine, Perugia, Italy; T. Bruce Ferguson Jr, MD, East Carolina Heart Institute, Greenville, NC; Robert A. Harrington, MD, Duke Clinical Research Institute, Durham, NC; Joerg Koglin, MD, Merck Research Laboratories, Rahway, NJ; Mark F. Newman, MD, Duke University Medical Center, Durham, NC; Nancy Nussmeier, MD, SUNY Upstate Medical University, Syracuse, NY; Ronald G. Pearl, MD, PhD, Stanford University School of Medicine, Palo Alto, Calif; Bertram Pitt, MD, University of Michigan School of Medicine, Ann Arbor, Mich; Andrew S. Wechsler, MD, Drexel University College of Medicine, Philadelphia, Pa; Richard D. Weisel, MD, University Health Network, Toronto, Ontario, Canada.

\section{STEERING COMMITTEE}

Stephen Fremes, MD, Sunnybrook Health Sciences Centre, Toronto, Ontario, Canada; Philippe Menasché, Prof, Département de Chirurgie Cardiovasculaire Hôpital Européen Georges Pompidou, Paris, France; Friedrich Wilhelm Mohr, Dr Prof, Herzzentrum Leipzig GmbH;
Klinik für Herzchirurgie, Leipzig, Germany; Ardawan J. Rastan, PD Dr med, Oberarzt Herzchirugie Herzzentrum der Universitat Leipzig, Leipzig, Germany; Axel Haverich, Prof Dr med Dr hc, Medizinische Hochschule Hannover Klinik für Herz-, Thorax-, Transplantations- und Gefässchirurgie, Hannover, Germany; Ugolino Livi, Prof, Dipartimento di Scienze Cardio-olmonari Ospedale S. Maria della Misericordia, Udine, Italy; Pieter Kappetein, Dr, Afdeling Thoraxchirurgie, Erasmus MC, Rotterdam, the Netherlands; Gonzalo Pradas, Dr, Hospital do Meixoeiro Servicio de Cirugia Cardiaca, Vigo, Spain; Robert A. Harrington, MD, Duke Clinical Research Institute, Durham, NC; Mark F. Newman, MD, Duke University Medical Center, Durham, NC; Elliott Bennett-Guerrero, MD, Duke Clinical Research Institute, Durham, NC; T. Bruce Ferguson, MD, East Carolina University Heart Institute, Greenville, NC; Linda Mongero, CCP, New York Presbyterian MC-Columbia, New York, NY; and Xing Li Wang, MD, PhD.

\section{DATA AND SAFETY MONITORING BOARD}

John H. Alexander, MD, MHS, Duke Clinical Research Institute, Durham, NC; Davy Cheng, MD, MSc, London Health Sciences Centre \& St Joseph Health Care, University of Western Ontario, London, Ontario, Canada; Frederick L. Grover, MD, University of Colorado Health Sciences Center, Aurora, Colo; Yuliya Lokhnygina, PhD, Duke Clinical Research Institute, Durham, NC; Hans-Christoph Diener, MD, University Duisburg-Essen, Essen, Germany. 
TABLE E1. Baseline characteristics

\begin{tabular}{|c|c|}
\hline Characteristic & $\mathbf{N}=\mathbf{3 0 8 0}$ \\
\hline \multicolumn{2}{|l|}{ Age, y } \\
\hline Mean (SD) & $66.5(8.6)$ \\
\hline Median (IQR) & $66.0(60.0-73.0)$ \\
\hline \multicolumn{2}{|l|}{ Sex, no. $(\%)$} \\
\hline Women & $1042(33.8)$ \\
\hline Men & $2038(66.2)$ \\
\hline \multicolumn{2}{|l|}{ Race/ethnicity, no. (\%) } \\
\hline White & 2687 (91.8) \\
\hline Nonwhite & $240(8.2)$ \\
\hline \multicolumn{2}{|l|}{ Body weight, $\mathrm{kg}$} \\
\hline Mean (SD) & $86.5(19.5)$ \\
\hline Median (IQR) & $85.0(73.0-98.0)$ \\
\hline \multicolumn{2}{|l|}{ Country of enrollment, no. (\%) } \\
\hline Canada & $303(9.8)$ \\
\hline France & $152(4.9)$ \\
\hline Germany & $446(14.5)$ \\
\hline Italy & $105(3.4)$ \\
\hline The Netherlands & $13(0.4)$ \\
\hline Spain & $75(2.4)$ \\
\hline United States & $1986(64.5)$ \\
\hline \multicolumn{2}{|l|}{ Cardiovascular history, no. (\%) } \\
\hline Hypertension & $2727(88.6)$ \\
\hline History of cigarette smoking & $1916(62.3)$ \\
\hline Hyperlipidemia & $2656(86.3)$ \\
\hline Diabetes mellitus & $1866(60.6)$ \\
\hline Family history of CAD & $1143(49.0)$ \\
\hline Prior MI & $1487(48.4)$ \\
\hline Prior angina & $1696(55.1)$ \\
\hline Prior stroke & $302(9.8)$ \\
\hline Prior transient ischemic attack & $186(6.0)$ \\
\hline Prior known carotid stenosis $\geq 50 \%$ & $373(12.1)$ \\
\hline Other CVD & $53(1.7)$ \\
\hline Prior PVD & $483(15.7)$ \\
\hline Claudication & $278(9.0)$ \\
\hline $\mathrm{HF}$ & $408(13.3)$ \\
\hline History/presence of AF or atrial flutter & $251(8.2)$ \\
\hline Prior PCI & $803(26.1)$ \\
\hline Prior CABG surgery & $153(5.0)$ \\
\hline Prior percutaneous carotid intervention & $43(1.4)$ \\
\hline Prior carotid endarterectomy & $123(4.0)$ \\
\hline $\begin{array}{l}\text { Peripheral arterial revascularization } \\
\text { (noncoronary, noncerebral) }\end{array}$ & $150(4.9)$ \\
\hline
\end{tabular}

$\overline{A F \text {, Atrial fibrillation; } C A B G \text {, coronary artery bypass grafting; } C A D \text {, coronary artery }}$ disease; $C V D$, cerebrovascular disease; $H F$, heart failure; $I Q R$, interquartile range; $M I$, myocardial infarction; $P C I$, percutaneous coronary intervention; $P V D$, peripheral vascular disease; $S D$, standard deviation.

TABLE E2. Intraoperative univariate predictors of the composite end point and each component

\begin{tabular}{lcccc}
\hline \multicolumn{1}{c}{ Variable name } & $\begin{array}{c}\text { 28-day } \\
\text { composite }\end{array}$ & $\begin{array}{c}\text { 28-day } \\
\text { death }\end{array}$ & $\begin{array}{c}\text { 28-day } \\
\text { NF-stroke }\end{array}$ & $\begin{array}{r}\text { 28-day } \\
\text { SLVD }\end{array}$ \\
\hline Last Hct before CABG end & 0.0172 & 0.2709 & 0.0187 & 0.9012 \\
Last Hgb before CABG end & 0.0217 & 0.0301 & 0.3501 & 0.4591 \\
Transfusion & 0.0723 & 0.3065 & 0.1469 & 0.0002 \\
Cardioplegia type & 0.2771 & 0.4315 & 0.8504 & 0.7492 \\
Cardioplegia temperature & 0.2232 & 0.7941 & 0.2543 & 0.1638 \\
Cardioplegia delivery method & 0.2975 & 0.5373 & 0.9139 & 0.0262 \\
No. of venous grafts & 0.9651 & 0.4408 & 0.4583 & 0.0455 \\
No. of arterial grafts & 0.5038 & 0.9096 & 0.8060 & 0.0732 \\
Duration of crossclamp (h) & 0.1890 & 0.1172 & 0.5542 & 0.0139 \\
Duration of CPB (h) & $<0.0001$ & $<0.0001$ & 0.6084 & $<0.0001$ \\
Atrial fibrillation before & 0.0112 & 0.1199 & 0.4285 & 0.2348
\end{tabular}

CABG end, per ECG

The final model included 5 covariates and had a $\mathrm{C}$-index of $\mathrm{C}=0.696$ (better than the preoperative model, which had a C-Index of 0.66 ) based on $\mathrm{N}=2897$ observations. The Hosmer-Lemeshow test for lack of fit was nonsignificant (chi-square $=4.98$, $P=.76) . C A B G$, Coronary artery bypass grafting; $C P B$, cardiopulmonary bypass; $E C G$, electrocardiogram; $H c t$, hematocrit; $H g b$, hemoglobin; $N F$, nonfatal; $S L V D$, severe left ventricular dysfunction.

TABLE E3. Univariate predictors of the composite end point and each component

\begin{tabular}{|c|c|c|c|c|}
\hline Variable name & $\begin{array}{l}\text { 28-day } \\
\text { composite }\end{array}$ & $\begin{array}{l}\text { 28-day } \\
\text { death }\end{array}$ & $\begin{array}{c}\text { 28-day } \\
\text { NF-stroke }\end{array}$ & $\begin{array}{l}\text { 28-day } \\
\text { SLVD }\end{array}$ \\
\hline Age at randomization & 0.0005 & 0.0219 & 0.0237 & 0.2605 \\
\hline Male gender & 0.0352 & 0.0220 & 0.8985 & 0.3458 \\
\hline $\mathrm{EF}$ & 0.0001 & 0.0512 & 0.7071 & $<0.0001$ \\
\hline No. of diseased vessels & 0.3767 & 0.6327 & 0.7616 & 0.0398 \\
\hline LMT $>50 \%$ stenosis & 0.4494 & 0.2920 & 0.5172 & 0.2027 \\
\hline $\begin{array}{l}\text { Evidence of preoperative } \\
\text { CVD }\end{array}$ & 0.0639 & 0.1760 & 0.0168 & 0.6818 \\
\hline History of PVD & 0.0022 & 0.0425 & 0.0216 & 0.4597 \\
\hline Prior PCI & 0.6341 & 0.1901 & 0.6108 & 0.9869 \\
\hline Prior CABG & 0.0390 & 0.1778 & 0.7037 & 0.0030 \\
\hline Prior HF & $<0.0001$ & 0.0321 & 0.3919 & $<0.0001$ \\
\hline Prior MI & 0.6951 & 0.8119 & 0.6302 & 0.1111 \\
\hline Hypertension & 0.5646 & 0.3165 & 0.4013 & 0.4131 \\
\hline Hyperlipidemia & 0.7015 & 0.0366 & 0.6724 & 0.9032 \\
\hline Diabetes & 0.8224 & 0.9903 & 0.1234 & 0.2254 \\
\hline Smoking & 0.3052 & 0.0576 & 0.9178 & 0.6262 \\
\hline Prior atrial fibrillation & 0.0201 & 0.0352 & 0.1622 & 0.8653 \\
\hline Aspirin before $\mathrm{CABG}$ & 0.0012 & $<0.0001$ & 0.6592 & 0.0230 \\
\hline Clopidogrel before CABG & 0.6031 & 0.6161 & 0.3835 & 0.7100 \\
\hline Anemia before CABG & 0.0168 & 0.0893 & 0.2377 & 0.3693 \\
\hline
\end{tabular}

